\title{
Using digital time-lapse cameras to monitor species-specific understorey and overstorey phenology in support of wildlife habitat assessment
}

\author{
Christopher W. Bater • Nicholas C. Coops • \\ Michael A. Wulder • Thomas Hilker • Scott E. Nielsen • \\ Greg McDermid • Gordon B. Stenhouse
}

Received: 6 July 2010 / Accepted: 21 October 2010 / Published online: 18 November 2010

(C) The Author(s) 2010. This article is published with open access at Springerlink.com

\begin{abstract}
Critical to habitat management is the understanding of not only the location of animal food resources, but also the timing of their availability. Grizzly bear (Ursus arctos) diets, for example, shift seasonally as different vegetation species enter key phenological phases. In this paper, we describe the use of a network of seven
\end{abstract}

C. W. Bater $(\varangle)$ · N. C. Coops · T. Hilker

Department of Forest Resources Management, University of British Columbia, 2424 Main Mall,

Vancouver, BC, V6T 1Z4, Canada

e-mail: cbater@interchange.ubc.ca

M. A. Wulder

Canadian Forest Service (Pacific Forestry Centre), Natural Resources Canada, 506 West Burnside Road,

Victoria, BC, V8Z 1M5, Canada

\section{S. E. Nielsen}

Department of Renewable Resources,

University of Alberta, 751 General Services Building,

Edmonton, Alberta, T6G 2H1, Canada

G. McDermid

Department of Geography, University of Calgary,

2500 University Drive NW, Calgary, Alberta, T2N

1N4, Canada

G. B. Stenhouse

Foothills Research Institute, Hinton, Alberta,

T7V 1X6, Canada ground-based digital camera systems to monitor understorey and overstorey vegetation within species-specific regions of interest. Established across an elevation gradient in western Alberta, Canada, the cameras collected true-colour (RGB) images daily from 13 April 2009 to 27 October 2009. Fourth-order polynomials were fit to an RGB-derived index, which was then compared to field-based observations of phenological phases. Using linear regression to statistically relate the camera and field data, results indicated that $61 \%$ ( $\left.r^{2}=0.61, \mathrm{df}=1, F=14.3, p=0.0043\right)$ of the variance observed in the field phenological phase data is captured by the cameras for the start of the growing season and $72 \%\left(r^{2}=0.72\right.$, df $=1$, $F=23.09, p=0.0009)$ of the variance in length of growing season. Based on the linear regression models, the mean absolute differences in residuals between predicted and observed start of growing season and length of growing season were 4 and 6 days, respectively. This work extends upon previous research by demonstrating that specific understorey and overstorey species can be targeted for phenological monitoring in a forested environment, using readily available digital camera technology and RGB-based vegetation indices.

Keywords Plant phenology •

Near-surface remote sensing •

Time-lapse photography $\cdot$ Ursus arctos 


\section{Introduction}

Managing landscapes for grizzly bears (Ursus arctos) is complicated given the diverse nature of food resources and habitats used by bears (McLellan and Hovey 2001; Hamer and Herrero 1987; Munro et al. 2006). The diet of grizzly bears has been studied for over two decades in many areas in North America and Europe, and is known to comprise seasonally abundant, nutrient-rich food (Hamer et al. 1991; Craighead et al. 1995; Dahle et al. 1998; Persson et al. 2001; Nielsen et al. 2003; Munro et al. 2006). Generally, their diet is highly diverse both temporally and spatially, as is the case for most habitat generalists or omnivores. Individual bears may in fact travel large distances to access high-quality food sources when they become seasonally available (Rogers 1987). In general, grizzly bear food habits and selection patterns following den emergence in the spring and prior to den entry in the fall may be divided into three distinct seasons: hypophagia, early hyperphagia and late hyperphagia (Nielsen 2005).
During hypophagia, grizzly bears feed on roots of Hedysarum spp. and occasionally carrion. During early hyperphagia, their diet extends to ants, ungulate calves and green herbaceous material such as cow-parsnip (Heracleum lanatum) and horsetail (Equisetum spp.). During the later season, berries such as buffalo berry (Shepherdia canadensis), blueberry (Vaccinium myrtilloides) and huckleberry (Vaccinium membranaceum), as well as the roots of Hedydarum spp., make up the majority of their diet (Nielsen 2005). Munro et al. (2006) grouped grizzly bear diet into nine major classes which differed seasonally and among mountain and foothills environments. Of the defined groups, animal matter was most important from late May to late June (most commonly moose, deer and elk), with a wide variety of green vegetation, including forbs and fruit, making up major components of their diet from late June through to early October (Fig. 1). Thus, grizzly bears rely on a variety of plant and animal species to satisfy their nutritional requirements, with individuals exhibiting seasonal shifts in diet and behaviour in

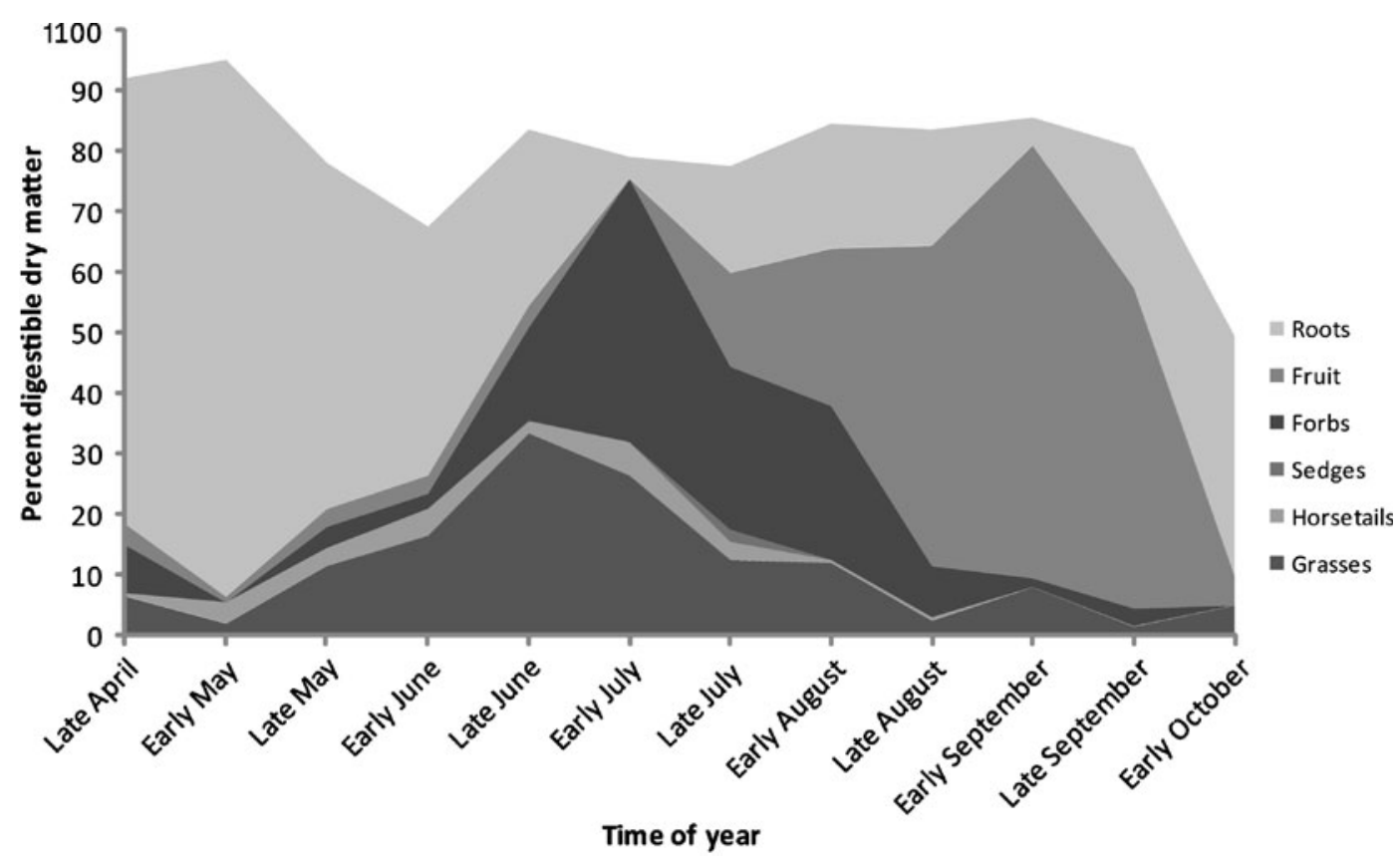

Fig. 1 Seasonal trends in digestible dry matter content of dominant vegetative food items found in grizzly bear feces collected in west-central Alberta between 2001 and 2003 (drawn using data from Munro et al. (2006), Table 2) 
response to changes in food availability (Munro et al. 2006). As a result, the development of spatially explicit food models operating at phenological scales matching those at which bears perceive and select resources is a critical step towards understanding their ecology (Nielsen et al. 2003, 2010).

One possible approach to determine seasonality in plant communities is to assess changes in the phenological stages through direct observation over multiple growing seasons and environmental conditions. While originally applied to carbon-related studies of vegetation, previous research indicates that changes in the timing of plant developmental phases may signal important inter-annual climatic variations (Reed et al. 1994; White and Nemani 2003; Xiao and Moody 2004), and may therefore be relevant to grizzly bear feeding patterns. Time series of phenology data can be developed using single or multiple observers at single locations, or through phenological networks, where multiple observers record observations of the same species at different locations (Bertin 2008). At broad spatial scales, satellite imagery, such as the normalized difference vegetation index, based on the normalized spectral reflectance in the red and near infrared regions of the electromagnetic spectrum, has been used for documenting patterns of 'leafing out' in spring (Botta et al. 2000; Studer et al. 2007). There are limitations, however, related to the broad spatial resolution of these sensors, which can be further exacerbated by poor temporal resolution in areas with persistent cloud cover. Other issues concerning satellite measurements are the need for adjustments due to changes in orbital and atmospheric conditions, and possible influences of late snow cover on the resultant data (Schwartz and Reed 1999; Studer et al. 2007).

The increasing popularity and use of inexpensive visible spectrum digital cameras in recent years offers the potential to remotely monitor and measure phenological events (Graham et al. 2006, 2010; Bradley et al. 2010). Repeat photography allows sampling at very dense temporal resolutions, often at daily or hourly intervals, for monitoring vegetation phenology. Mounting these systems on towers or other platforms provides data at an intermediate scale of observation, al- lowing a contrast between field-based observations and satellite-derived measures (Richardson et al. 2009). Close-range observation, often referred to as near-surface remote sensing, facilitates the collection of high temporal and spatial resolution data.

Many of the early applications of camera technology to phenological studies started in agriculture (Adamsen et al. 2000). For example, Purcell (2000) utilised digital cameras to detect changes in wheat and soybean canopies at a 1-m spatial resolution over a growing season. Graham et al. (2006) acquired daily images of mosses during drying and moistening cycles to develop a comprehensive understanding of the changing status of the species under different climatic conditions. Richardson et al. (2007) recently mounted a commercially available digital web camera system on a $\mathrm{CO}_{2}$ flux tower in Barlett, New Hampshire, to observe deciduous vegetation green-up and to make comparisons to changes in the fraction of the photosynthetically active radiation absorbed by the canopy. After initial success using data obtained in 2006, a network of similar instruments is being proposed to be installed on a larger number of flux tower sites across North America, and potentially as part of the National Ecological Observation Network (described in Keller et al. (2008)). Linking the phenological cycle through these types of measurements to the drivers of habitat and food availability for animal species sensitive to phenological events has the potential to be incorporated into wildlife habitat and nutritional landscape models (Nielsen et al. 2003, 2010) and provide further insight into the changing needs of animals. Grizzly bears in western Alberta are particularly good candidates for a study of this type, as an extensive body of knowledge related to their seasonal feeding habits and home range usage exists.

In this paper, we demonstrate the potential for imagery collected from a network of cameras established across an elevation gradient in western Alberta to be used to derive phenological patterns of food species commonly used by grizzly bears. We focus on 11 "regions of interest" within the ground-based images delineating under- and overstorey species, many relevant to bear diets, to assess the capacity of the network to detect changes 
in phenological phases and correlate these indicators with field observations.

\section{Materials and methods}

Study area

The eastern slopes of the Rocky Mountains in Alberta, Canada, is a diverse region containing a mix of mature and young forest, wetlands and alpine areas. A 90-km-long transect centred near the town of Robb, Alberta $\left(53.2215^{\circ} \mathrm{N}\right.$, $116.98392^{\circ} \mathrm{W}$ ), was designed to capture a range of phenological changes and growing seasons attributes across known grizzly bear habitat. Six sites were selected in pairs at three different elevation zones across the transect. One paired site was placed within a coniferous dominated stand, and the other paired site located in a more mixed species site with between $20-40 \%$ deciduous trees. Additionally, a seventh site was established in a high-elevation coniferous stand, but no mixed replicate could be found. Details on the sites, their vegetation composition and location are summarized in Table 1.
Digital camera network setup

A detailed description of the phenological camera network is provided in Bater et al. (Design and installation of a camera network across an elevation gradient for habitat assessment. Instrumentation Science \& Technology, submitted). In summary, seven commercially available digital time-lapse camera systems manufactured by Harbortronics (Fort Collins, Colorado, USA) were installed (Table 2). The systems consist of a Pentax digital single lens reflex camera slaved to an intervalometer, which are sealed in a fiberglass case. Power was provided by a solar panel and a lithium ion battery. The cameras employ $23.5 \times$ $15.7 \mathrm{~mm}$ charged coupled device (CCD) sensors with either 6.1 or 10.2 million effective pixels with data recorded using a 4 GB SD memory card. In each plot, a single camera was mounted $3 \mathrm{~m}$ above the ground on a tall and dominant tree and pointed north. To minimize directional effects caused by solar movements, each camera was set to record five JPEG images per day between 12:00 noon and 1:00 p.m. local time. Digital images were archived as high-resolution JPEG images $(2,000 \times$ 3,008 pixel or $2,592 \times 3,872$ pixel resolution with

Table 1 Summary of the camera sites, including forest cover type and coordinates

\begin{tabular}{|c|c|c|c|c|c|}
\hline Site name & Easting $(\mathrm{m})^{\mathrm{a}}$ & Northing $(\mathrm{m})^{\mathrm{a}}$ & Forest type & $\begin{array}{l}\text { Forest composition and } \\
\text { common names (basal area) }\end{array}$ & Elevation $(\mathrm{m})^{\mathrm{b}}$ \\
\hline Bryan spur & 502,319 & $5,899,684$ & Mixed & $\begin{array}{l}\text { Lodgepole pine }\left(16 \mathrm{~m}^{2} / \mathrm{ha}\right) \\
\text { trembling aspen }\left(10 \mathrm{~m}^{2} / \mathrm{ha}\right) \\
\text { and spruce species }\left(2 \mathrm{~m}^{2} / \mathrm{ha}\right)\end{array}$ & 1,093 \\
\hline Bryan spur & 501,950 & $5,898,930$ & Coniferous & $\begin{array}{l}\text { Open black spruce forest } \\
\left(10 \mathrm{~m}^{2} / \mathrm{ha}\right), \text { bog }\end{array}$ & 1,092 \\
\hline Fickle Lake & 519,136 & $5,916,668$ & Mixed & $\begin{array}{l}\text { White spruce }\left(22 \mathrm{~m}^{2} / \mathrm{ha}\right) \\
\text { trembling aspen }\left(18 \mathrm{~m}^{2} / \mathrm{ha}\right), \\
\text { dead balsam poplar }\left(4 \mathrm{~m}^{2} / \mathrm{ha}\right), \\
\text { closed forest }\end{array}$ & 970 \\
\hline Fickle Lake & 518,537 & $5,916,058$ & Coniferous & $\begin{array}{l}\text { Riparian white spruce forest } \\
\left(14 \mathrm{~m}^{2} / \mathrm{ha}\right), \text { bog }\end{array}$ & 951 \\
\hline Cadomin & $\begin{array}{r}478,427 \\
1,484\end{array}$ & $5,877,276$ & Mixed & $\begin{array}{l}\text { Riparian, balsam poplar }\left(6 \mathrm{~m}^{2} / \mathrm{ha}\right) \\
\text { and white spruce }\left(4 \mathrm{~m}^{2} / \mathrm{ha}\right)\end{array}$ & \\
\hline Cadomin & 480,660 & $5,879,755$ & Coniferous & $\begin{array}{l}\text { Open black spruce forest }\left(6 \mathrm{~m}^{2} / \mathrm{ha}\right) \text {, } \\
\text { occasional lodgepole pine, bog }\end{array}$ & 1,458 \\
\hline Prospect Creek & 478,036 & $5,868,840$ & Coniferous & $\begin{array}{l}\text { High elevation, lodgepole } \\
\text { pine }\left(20 \mathrm{~m}^{2} / \mathrm{ha}\right)\end{array}$ & 1,714 \\
\hline
\end{tabular}

a Projection: Universal Transverse Mercator. Horizontal Datum: World Geodetic System 1984. Zone: 11 north

bEllipsoid: World Geodetic System 1984 
Table 2 Description of the intervalometers and cameras employed for the phenology monitoring program

\begin{tabular}{lll}
\hline Intervalometer & Model & Harbortronics Digisnap 2000 \\
& Time of first daily capture & $12: 00$ noon \\
& Number of captures & 5 \\
& Interval between captures & 12 min \\
\hline Camera & Model & Pentax K100D or K200D digital \\
& Sensor & single lens reflex \\
& $23.5 \times 15.7$ mm CCD; 6.1 or \\
& Lens & 10.2 million effective pixels \\
Card & $18-55$ mm, f 3.5-5.6 \\
File type & 4 GB SD \\
White balance & High-quality JPEG \\
Mode & Sunlight \\
ISO & Program auto exposure $(P)$ \\
Focus & 200 \\
Focal length & Manual, set to infinity \\
Shake reduction & 18 mm \\
Flash & Disabled \\
& Disabled \\
\hline
\end{tabular}

three channels of 8-bit RGB data). Image file ancillary data included date and time of acquisition. The cameras collected imagery for a single growing season in 2009, operating from 13 April (day of year $=103$ ) to 27 October (day of year $=300)$.

Field validation and phenophase codes

The seven camera locations were visited 12 times throughout the growing season, and vegetation were classified using phenophase codes developed

Table 3 Phenology codes developed by Dierschke (1972) and recorded at monitoring sites for trees and shrubs

\begin{tabular}{|c|c|}
\hline Vegetative (V) & \\
\hline Deciduous tree or shrub & Conifer \\
\hline 0. Closed bud & 0. Closed bud \\
\hline $\begin{array}{l}\text { 1. Green leaf out but } \\
\text { not unfolded }\end{array}$ & 1. Swollen bud \\
\hline $\begin{array}{l}\text { 2. Green leaf out, start } \\
\text { of unfolding }\end{array}$ & 2. Split bud \\
\hline 3. Leaf unfolding up to $25 \%$ & 3. Shoot capped \\
\hline 4. Leaf unfolding up to $50 \%$ & 4. Shoot elongate \\
\hline 5. Leaf unfolding up to $75 \%$ & $\begin{array}{l}\text { 5. Shoot full length, } \\
\text { lighter green }\end{array}$ \\
\hline 6. Full leaf unfolding & $\begin{array}{l}\text { 6. Shoot mature, } \\
\text { equally green }\end{array}$ \\
\hline \multicolumn{2}{|l|}{ 7. Stem/first leaves fading } \\
\hline \multicolumn{2}{|l|}{ 8. Yellowing up to $50 \%$} \\
\hline \multicolumn{2}{|l|}{ 9. Yellowing over $50 \%$} \\
\hline 10. Dead & \\
\hline
\end{tabular}

by Dierschke (1972) (Table 3). Codes for deciduous vegetation ranged from 0 indicating closed bud, through to 6 (full leaf unfolding), to 10, which represents dead vegetation. In the case of coniferous green vegetation, the codes ranged from 0 to 6 , indicating closed bud (0) through to mature shoots (6).

Image analysis

Eleven homogenous under- and overstorey species-specific regions of interest, observable on the digital camera imagery, were selected from the photos in order to assess vegetation development at a high level of detail (Fig. 2, Table 4). Using regions of interest or masks is a commonly accepted method for analysing specific portions of ground-based images. For example, Ahrends et al. (2008) employed regions of interest to isolate portions of individual ash and beech crowns from a mixed canopy beneath a flux tower. Ide and Oguma (2010) employed areas or regions of interest to separate individual species where image resolution and distance to target permitted. Graham et al. (2010) segmented images into deciduous, evergreen and understorey regions for analysis.

The selection of an accurate vegetation index is required for automated image-based analyses of plant phenology. Previously, Woebbecke et al. (1995) investigated five true-colour indices 


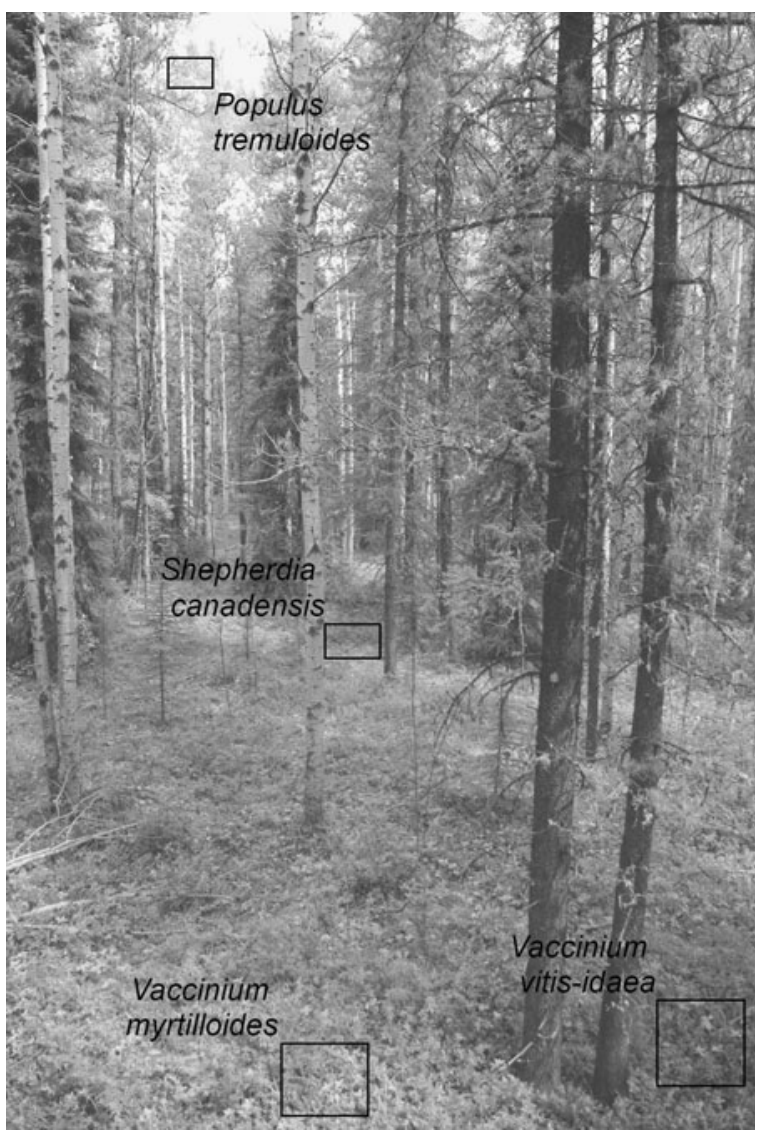

Fig. 2 Black and white example of a photo acquired at the Bryan Spur mixed site, and size and positions of speciesspecific regions of interest which were analyzed

derived from digitized images to separate living plant material from soil and crop residue. Woebbecke et al. (1995) determined that an excess green index was most effective, and it has been used widely since (e.g. Meyer and Neto 2008). Recently, Richardson et al. (2007) developed a phenology monitoring program using a digital RGB web camera, and employed a measure similar to the excess green index referred to as $2 \mathrm{G}-\mathrm{RBi}$ :

$2 \mathrm{G}-\mathrm{RBi}=2 \mu_{G}-\left(\mu_{R}+\mu_{B}\right)$

where $\mu_{G}, \mu_{R}$ and $\mu_{B}$ are the camera observed brightness values (raw DN) in the green, red and blue channels, respectively. Richardson et al. (2007) found good correlations between vegetation gross primary production as measured from an eddy flux covariance tower. Thus, rather than using a satellite-derived vegetation index, we employed the $2 \mathrm{G}-\mathrm{RBi}$ index to monitor changes in plant phenology within each species-specific region of interest (Fig. 2).

Many approaches have been developed to interpret phenological events from temporal variations in vegetation indices or, in this situation, sequential digital imagery. Information on key dates, such as the start and end of the growing season are possible (Waring et al. 2006). One key method to extract these dates is based on the seasonal-midpoint (or half-maximum) approach, which was designed to predict the initial leaf expansion of broadleaf forests (White et al. 1999; Schwartz et al. 2002). The method first calculates the annual minimum and maximum value for each pixel and the midpoint is then calculated and added to the minimum. This calculated value has the advantage over other formulations in that it is sensitive to site-specific variations in the range of values
Table 4 Vegetation species monitored within image regions of interest

\begin{tabular}{lll}
\hline Site & Region of interest species & $\begin{array}{l}\text { Region of interest } \\
\text { species common name }\end{array}$ \\
\hline Bryan Spur Mixed & $\begin{array}{l}\text { Populus tremuloides } \\
\text { Vaccinium vitis-idaea } \\
\text { Vaccinium myrtilloides } \\
\text { Shepherdia canadensis }\end{array}$ & $\begin{array}{l}\text { Trembling aspen } \\
\text { Lingon berry }\end{array}$ \\
& Populus tremuloides & Hillside blueberry \\
Fickle Lake Mixed & Shepherdia canadensis & Buffalo berry \\
Fickle Lake Conifer & Equisetum arvense & Buffalo berry \\
Cadomin Mixed & Populus balsamifera & Common horsetail \\
& Shepherdia canadensis & Balsam poplar \\
Cadomin Conifer & Equisetum arvense, grass & Buffalo berry \\
Prospect Creek & Shepherdia canadensis & Horsetail, grass \\
\hline
\end{tabular}



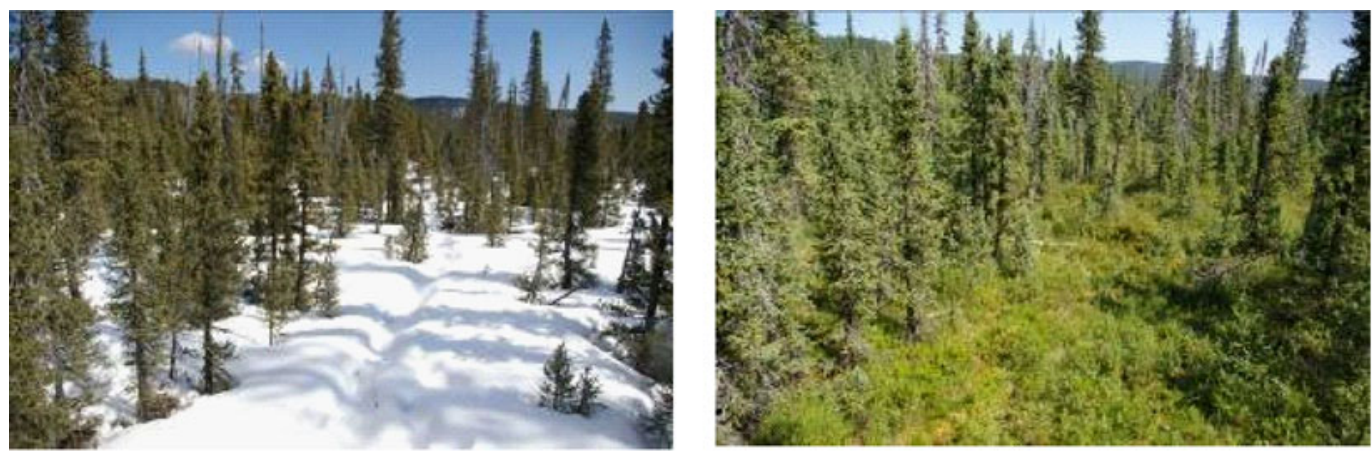

14 April

7 August

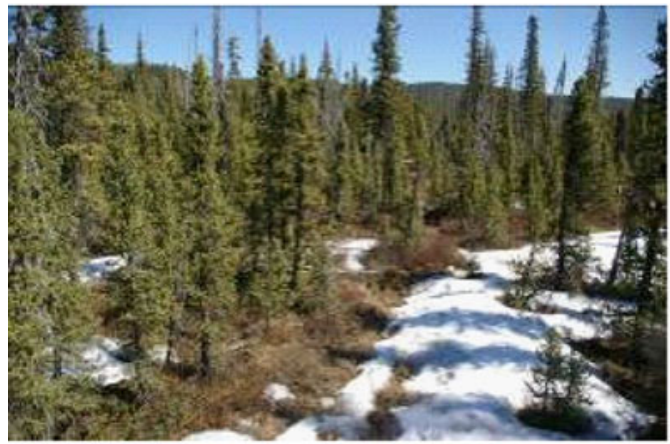

4 May
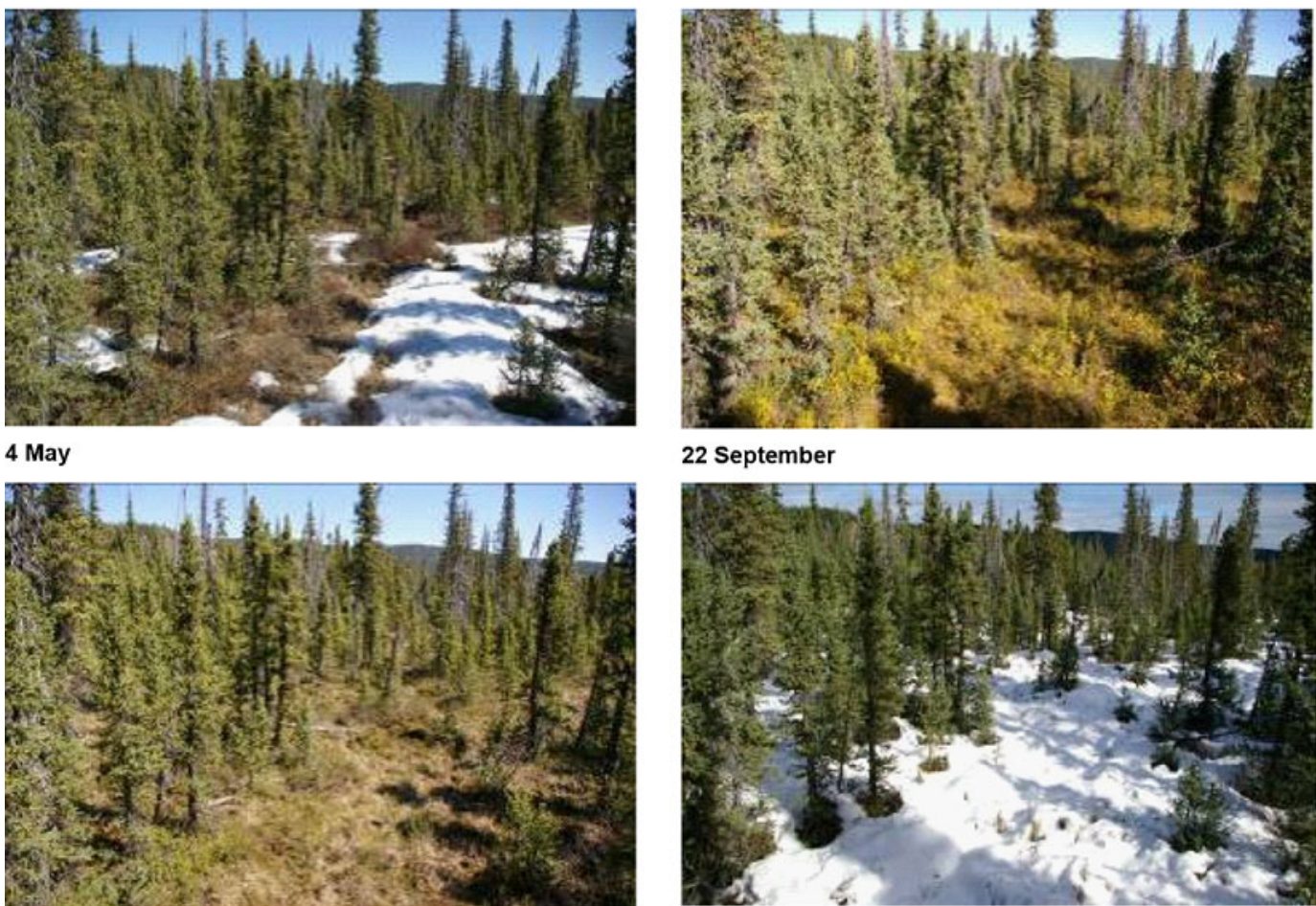

9 June

\section{September}
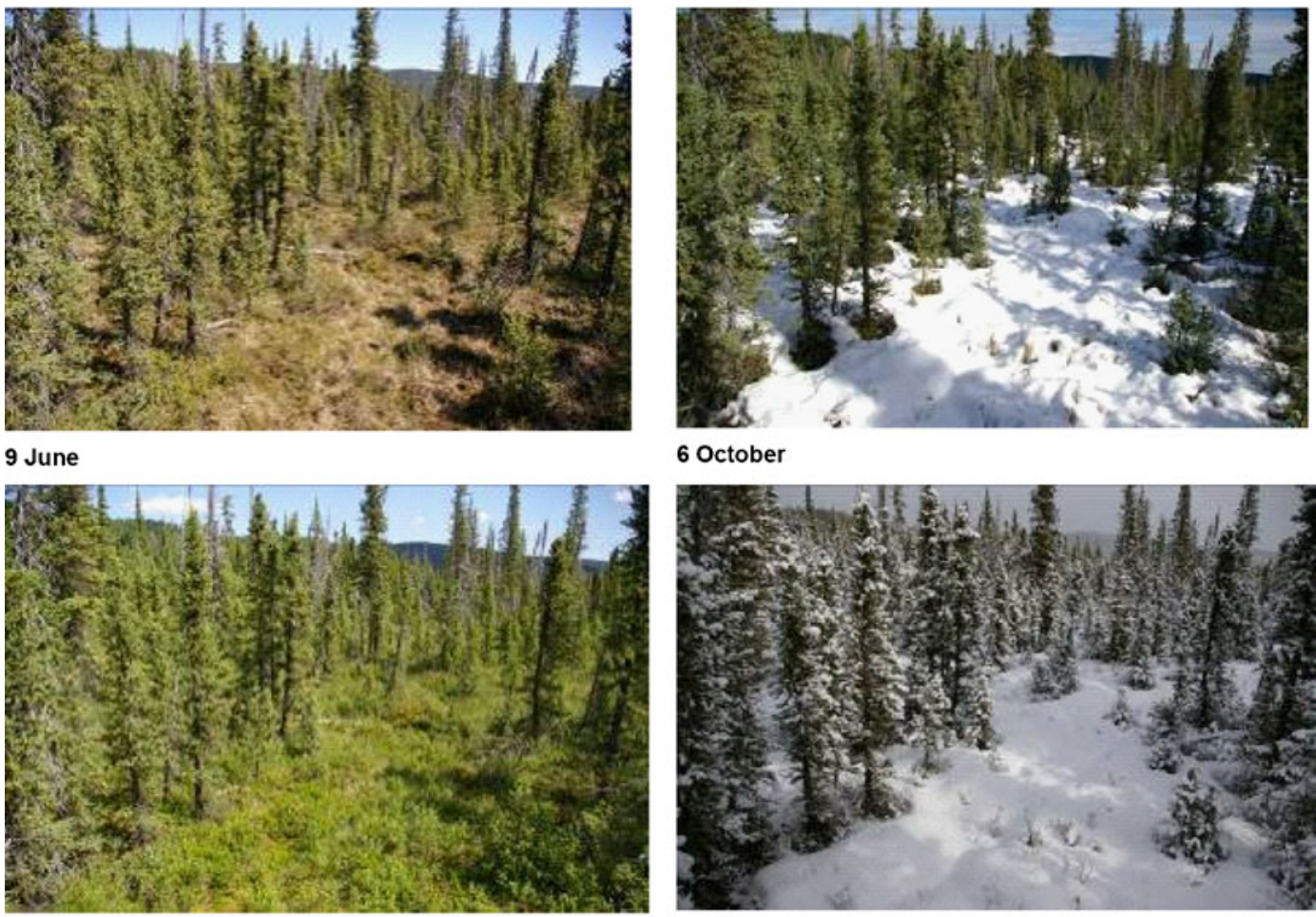

17 July

\section{October}

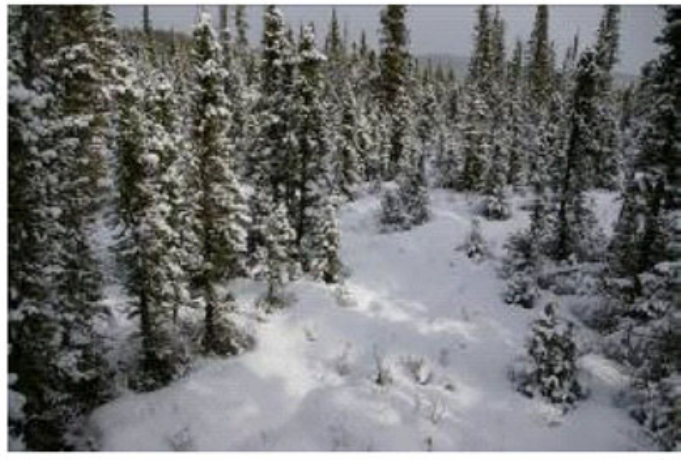

27 October

Fig. 3 Selection of seasonal images acquired from the Cadomin conifer site 
Fig. 4 Standardized curves showing growing season trends in mean daily temperature and the global (image-wide) $2 \mathrm{G}-\mathrm{RBi}$ index for the Bryan Spur mixed site, and noon sun elevation at Robb, Alberta

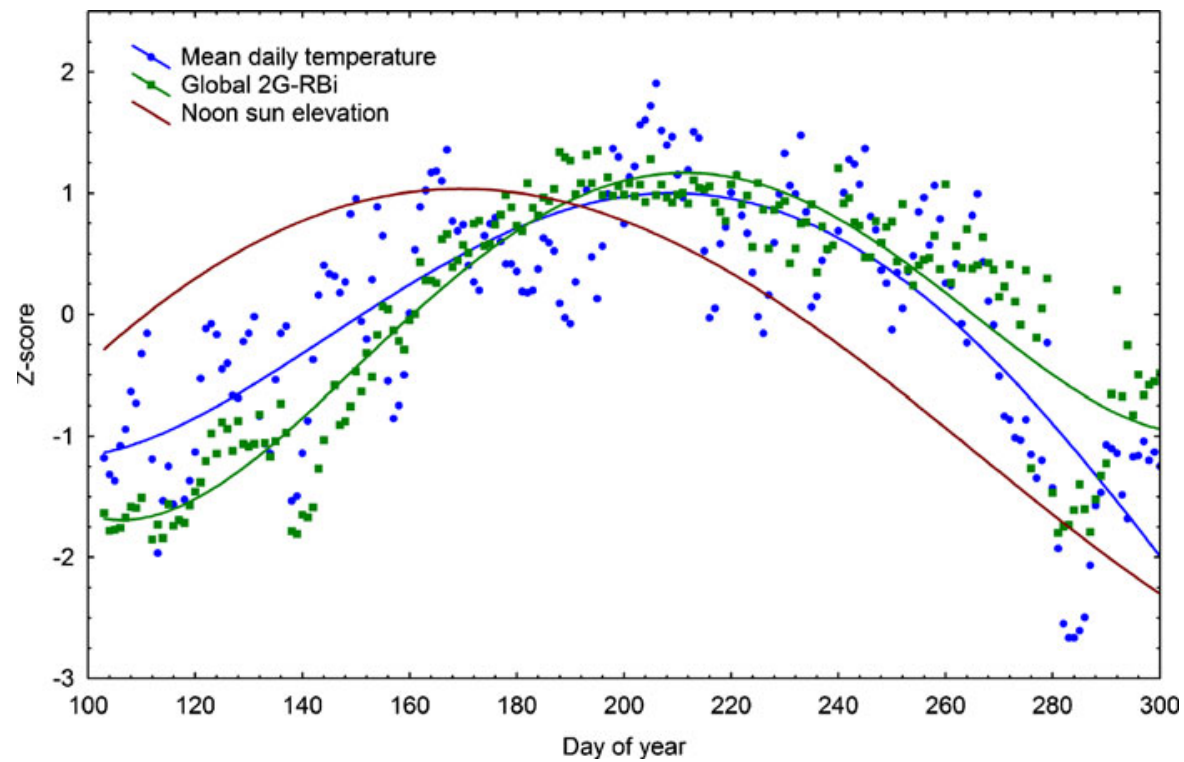

and may be more sensitive to local variation in canopy leaf area and chlorophyll concentrations (Waring et al. 2006).

Once 2G-RBi values were calculated for each region of interest within the images for the du- ration of the observation period, curves were fitted to the data to estimate green-up and senescence. Using Landsat-derived indices, Fisher et al. (2006) demonstrated that a logistic-growth simulating sigmoid curve could be employed to
Fig. 5 Graphic representation of the formulation of the mean 2G-RBi index through the growing season, and the field-based phenocode values

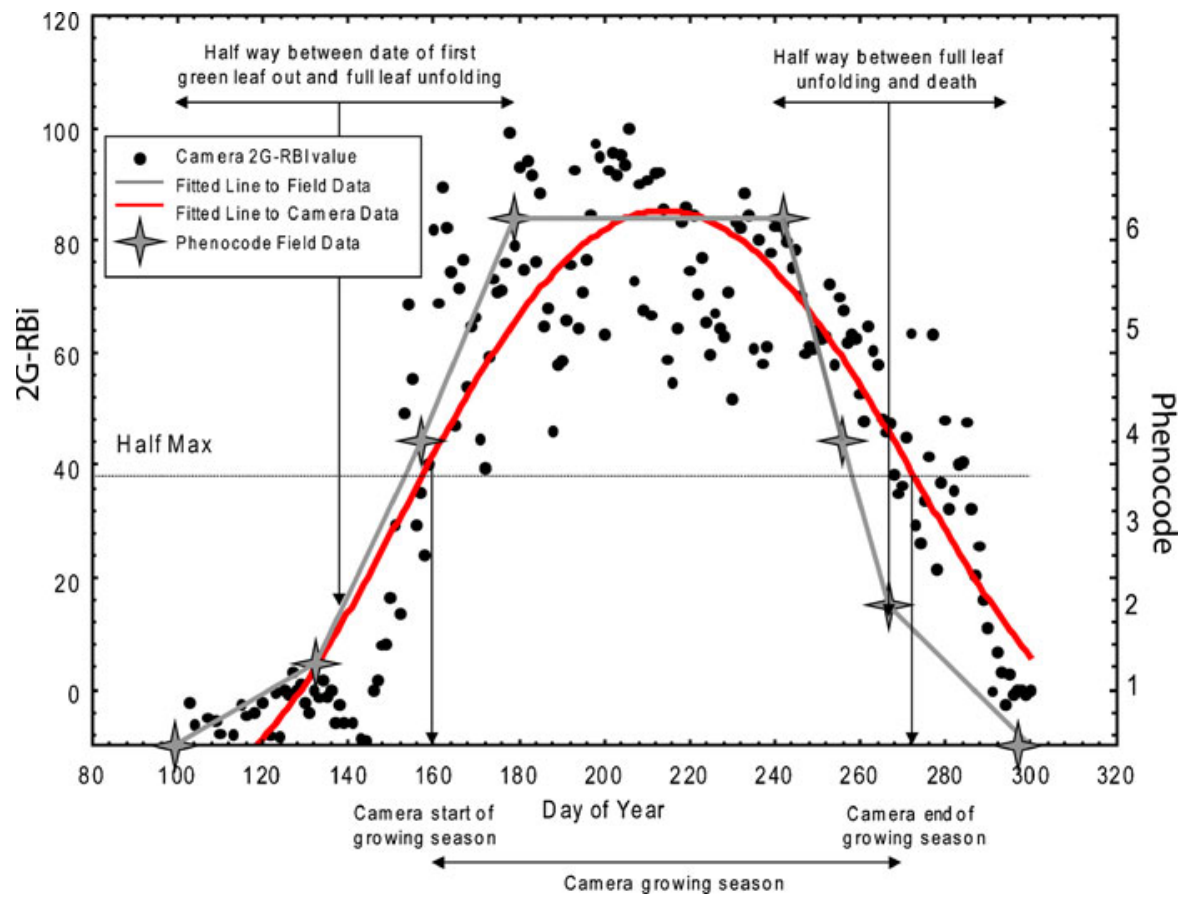


Fig. 6 Example of temporal sequence of 2G-RBI and phenocode values for four species-specific regions of interest at three vegetation sites in the study area
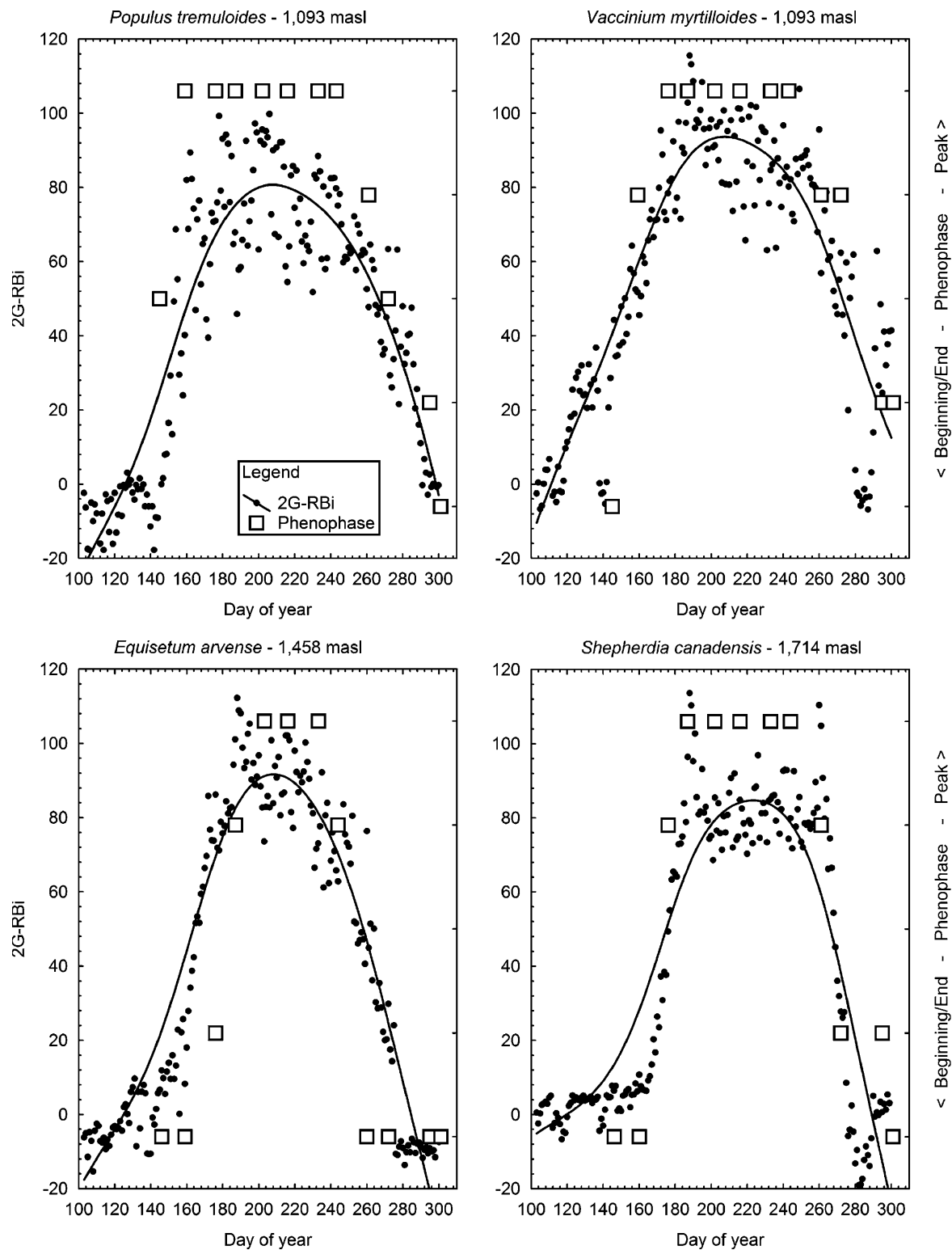

estimate leaf onset and offset. The method was improved upon by Soudani et al. (2008), who employed MODIS data to derive vegetation phenology dates. Similarly, using tower-based digital images, Richardson et al. (2009) used two sigmoid functions multiplied together to fit curves to relative channel brightness values observed by the camera system, and then used the inflection points to mark the beginning and end of the season in broadleaf and conifer forest canopies. In this study, we adapted the method and used a fourth-order polynomial function, rather than a sigmoid, to fit the $2 \mathrm{G}-\mathrm{RBi}$ observations throughout the observation period. Null and inflection points were determined using the first, second and third derivatives of the polynomial, and were used to define the day of year of the initial green-up, maximum greenness and end of the growing season. Using linear regression, statistical relationships were then developed between the human 
observed assessments of phenological phases and the $2 \mathrm{G}-\mathrm{RBi}$ data obtained from the speciesspecific regions of interest within the images.

\section{Results}

Over the installation period from 13 April 2009 to 27 October 2009, more than 6,700 images were acquired across the seven sites. A $10 \%$ failure rate was due largely to battery failure where light levels below the canopy were not sufficient for the camera units' solar panels to maintain charge. Figure 2 is a grayscale image example of the Bryan Spur mixed site with regions of interest over three understorey and one overstorey species. It is from regions of interest such as these that the imagebased indices were calculated. Figure 3 shows an example of images collected at the Cadomin Conifer site, and indicates the variability of the scenes with respect to the overstorey and understorey composition, as well as snow cover at the commencement and end of the growing season.

Figure 4 shows fourth-order polynomials fit to daily noon sun elevation angles at Robb, Alberta, and mean daily temperature and mean daily scene-wide 2G-RBi at the adjacent Bryan Spur mixed site. The trends indicate that the $2 \mathrm{G}-\mathrm{RBi}$ signal is related to temperature-induced changes in plant phenology, and not simply a seasonal fluctuation in scene brightness related to sun elevation angle.
An example of a temporal sequence of mean daily $2 \mathrm{G}-\mathrm{RBi}$ values for a single region of interest, and the species-specific phenological trajectory as measured during field visits, is shown in Fig. 5. The implementation of the half-maximum parameter approach produced a range of start and end of growing season dates across the 11 species-specific regions of interest, and range from day 133 as observed by the camera, through to day 190 as observed from the field-based observations. Similarly, the growing season length as estimated using the half maximum method ranged from 65 days for the field observations, to 148 days using the camera data. As would be anticipated, the start of the growing season was generally later, and length of growing season shorter, for high elevation sites (start of growing season mean $=$ day 175 , length of growing season $=80$ days) compared to those at lower elevations (start of growing season mean $=$ day 170 , length of growing season $=$ 110 days).

Figure 6 shows additional examples comparing the 2G-RBi calculated for species-specific regions of interest to the field-based phenophase measurements for four species at three sites. On average, the first $2 \mathrm{G}-\mathrm{RBi}$ half maximum inflection points occurred 21 days before the beginning of the growing season as observed in the field, while the length of time between the first and last half-maximums were 21 days greater than those measured in the field. Based on linear regression models, the relationship between the field and
Fig. 7 Results of the linear regression analyses using the camera-derived $2 \mathrm{G}-\mathrm{RBi}$ as a predictor variable. Predicted vs. observed (left) start of growing season $\left(r^{2}=\right.$ $0.61, \mathrm{df}=1, F=14.3$, $p=0.0043)$ and (right) length of growing season $\left(r^{2}=0.72, \mathrm{df}=1, F=\right.$ 23.09, $p=0.0009$ )
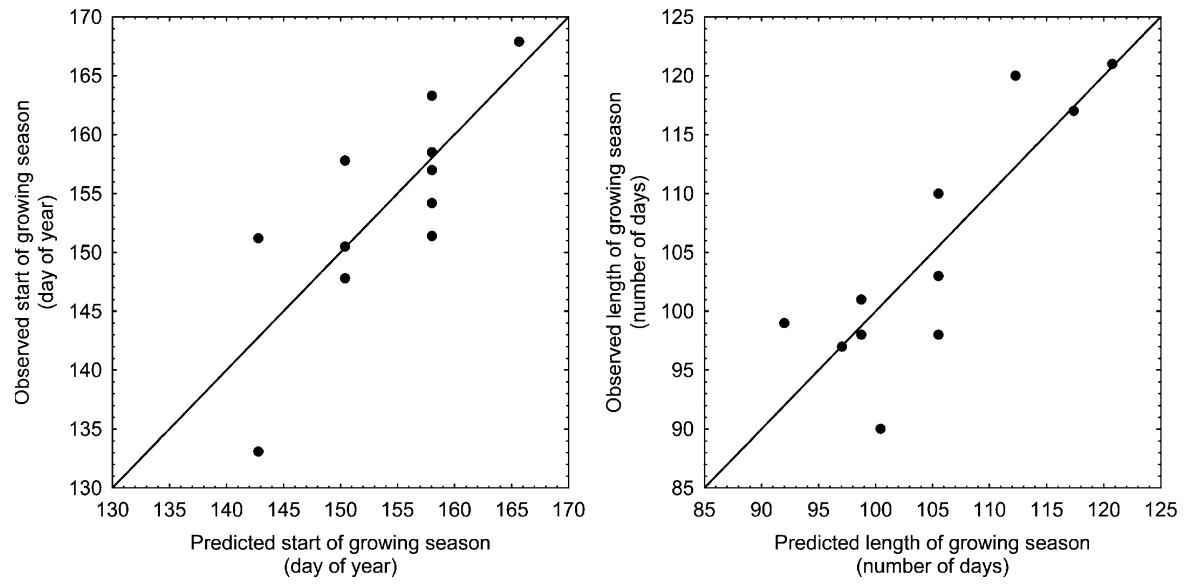
camera data indicates that $61 \%\left(r^{2}=0.61, \mathrm{df}=\right.$ $1, F=14.3, p=0.0043)$ of the variance observed in the field measures of phenological phases were captured by the camera for the start of the growing season, and $72 \%\left(r^{2}=0.72, \mathrm{df}=1, F=23.09\right.$, $p=0.0009)$ of the variance in length of growing season (Fig. 7). The mean absolute differences in residuals between predicted and observed start of growing season and length of growing season were 4 and 6 days, respectively (Fig. 7).

\section{Discussion and conclusion}

The development of ground-based remote sensing networks, such as the one described in this paper, provide the tools necessary for improving our understanding of the seasonal variations in vegetation phenology, and will ultimately lead to improved detection of changing vegetation characteristics for wildlife management. In addition, ground-based camera systems can provide high temporal resolution for calibration of satellite-based monitoring initiatives. This study expands on the previous work of others, such as Richardson et al. (2007), Ahrends et al. (2008) and Richardson et al. (2009), by demonstrating that ground-based cameras can be employed to simultaneously monitor species-specific overstorey and understorey phenology. In particular, the establishment of the network in a forest environment, without the need for infrastructure such as a flux tower, greatly improves flexibility.

Although growing season start and end dates were successfully estimated using the halfmaximum approach, a limitation of working at the plot scale was the inability to detect subtle phenological events critical for wildlife habitat (food) modelling. For instance, the precise timing of initial leaf unfolding or the development of fruiting bodies was difficult to capture when vegetation was at a distance from the cameras. Further research is required to determine how best to capture these events, and whether they can be related to other phenological measures that are easily observed at a distance. A possible solution may be a more focused targeting of individual plants, and the investigation of possible relationships between image-derived indices such as the $2 \mathrm{G}-\mathrm{RBi}$, and biological events such as fruit ripening. Placing cameras in greater proximity to individual plants may also offer the advantage of reduced frequency of field visits for collection of phenological phase data, which could conceivably be interpreted directly from the images.

Our results indicate that some biases exist between the timing of the half maximum and the field-based estimates of growing season, which was partly the result of differences in the nature of the two data sets. The camera data provides a daily indication of greenness, but is heavily influenced by hourly, daily and seasonal changes in illumination. The field observations, which are based on weekly interpretations by ground crews and account for overall leaf and plant condition, are not quantitative measurements of changes in plant biochemical composition. Nonetheless, the cameras effectively captured a range of phenological conditions for multiple species found at the sites along the transect, and the data they collect represent both a spectral and visual record for later use.

Grizzly bears use a variety of food resources which are both seasonally and spatially dynamic. Current wildlife models, however, lack the spatial and temporal resolution to predict habitat use at the scales in which animals respond to their environment (Nielsen et al. 2010). A possible solution may be the development of landscape models with greater temporal and spatial resolutions using data fusion algorithms such as those developed by Gao et al. (2006). Landsat, MODIS or other remotely sensed information could then be used to generate dense time-series representing important phenological developments or stages of critical food resources. Ground-based cameras would thereby provide an important source of information for model calibration or validation. This is particularly important for habitats associated with rare species, such as grizzly bears, given the difficulty of repeatedly visiting remote sites at the frequency and quality necessary for detecting changes in critical food resources. We suggest that better spatially explicit predictions of the timing of these events will lead to a better understanding of relationships between climate, local and landscape patterns of food availability and quality, and the responses of these changes and patterns by 
individual animals (e.g. body size and growth) or populations. Critical to accomplishing this for grizzly bears will be the integration of technologies, including satellite and ground-based remote sensing platforms, to measure vegetation phenology; field and laboratory-based measures of nutrient quality in target plant foods; knowledge of the distribution and abundance of food resources; the behavioral responses of animals to environmental changes; and measures of animal health or population dynamics. Linking these research elements will ultimately lead to a broader understanding of grizzly bear ecology and thus better management and conservation of the species.

Acknowledgements Sam Coggins (University of British Columbia) and David Laskin (University of Calgary) were members of the deployment team. Karen Graham (Foothills Research Institute) and Tracy McKay (Foothills Research Institute) were members of the phenophase field monitoring team. Raphaël Roy-Jauvin provided assistance with figures. Andrew Richardson (Harvard University) and Scott Ollinger (University of New Hampshire) provided initial advice and enthusiasm for the network plans. Funding for this research was partially provided by the Grizzly Bear Program of the Foothills Research Institute located in Hinton, Alberta, Canada, with additional information available at http://www.foothillsresearchinstitute.ca/. Funding was also provided by the Canadian Forest Service, the University of British Columbia and an NSERC Discovery grant to Coops.

Open Access This article is distributed under the terms of the Creative Commons Attribution Noncommercial License which permits any noncommercial use, distribution, and reproduction in any medium, provided the original author(s) and source are credited.

\section{References}

Adamsen, F. J., Coffelt, T. A., Nelson, J. M., Barnes, E. M., \& Rice, R. C. (2000). Method for using images from a color digital camera to estimate flower number. Crop Science, 40, 704-709.

Ahrends, H. E., Brügger, R., Stöckli, R., Schenk, J., Michna, P., Jeanneret, F., et al. (2008). Quantitative phenological observations of a mixed beech forest in northern Switzerland with digital photography. Journal of Geophysical Research, 113, G04004. doi:10.1029/2007JG000650.

Bertin, R. I. (2008). Plant phenology and distribution in relation to recent climate change. The Journal of the Torrey Botanical Society, 135, 126-146.
Botta, A., Viovy, N., Ciais, P., Friedlingstein, P., \& Monfray, P. (2000). A global prognostic scheme of leaf onset using satellite data. Global Change Biology, 6, 709-725.

Bradley, E., Roberts, D., \& Still, C. (2010). Design of an image analysis website for phenological and meteorological monitoring. Environmental Monitoring and Software, 25, 107-116.

Craighead, J. J., Sumner, J. S., \& Mitchell, J. A. (1995). The grizzly bears of Yellowstone: Their ecology in the Yellowstone Ecosystem, 1959-1992. Washington DC: Island Press.

Dahle, B., Sørensen, O. J., Wedul, E. H., Swenson, J. E., \& Sandegren, F. (1998). The diet of brown bears Ursus arctos in central Scandinavia: Effect of access to freeranging domestic sheep Ovis aries. Wildlife Biology, 4, 147-158.

Dierschke, H. (1972). On the recording and presentation of phenological phenomena in plant communities. English translation of: Zur Aufnahme und Darstellung phänologischer Erscheinungen in Pflanzengesellschaften. The Hague: Translated by R.E. Wessell and S.S. Talbot. 1970 International Symposium for Vegetation Science.

Fisher, J. I., Mustard, J. F., \& Vadeboncoeur, M. A. (2006). Green leaf phenology at Landsat resolution: Scaling from the field to the satellite. Remote Sensing of Environment, 100, 265-279.

Gao, F., Masek, J., Schwaller, M., \& Hall, F. (2006). On the blending of the Landsat and MODIS surface reflectance: Predicting daily Landsat surface reflectance. IEEE Transactions on Geoscience and Remote Sensing, 44, 2207-2218.

Graham, E. A., Hamilton, M. P., Mishler, B. D., Rundel, P. W., \& Hansen, M. H. (2006). Use of a networked digital camera to estimate net $\mathrm{CO}_{2}$ uptake of a desiccation-tolerant moss. International Journal of Plant Sciences, 167, 751-758.

Graham, E. A., Riordan, E. C., Yuen, E. M., Estrin, D., \& Rundel, P. W. (2010). Public Internet-connected cameras used as a cross-continental ground-based plant phenology monitoring system. Global Change Biology, 16, 3014-3023. doi:10.1111/j.1365-2486.2010. 02164.x.

Hamer, D., \& Herrero, S. (1987). Grizzly bear food and habitat in the front ranges of Banff National Park, Alberta. In Zager, P. (ed.), Proceedings of 7th International Conference on Bear Research and Management (pp. 199-213). Williamsburg, Va, U.S.A and Plityice Lakes, Yugoslavia, February and March 1986: International Association of Bear Research and Management.

Hamer, D., Herrero, S., \& Brady, K. (1991). Food and habitat used by grizzly bears, Ursus arctos, along the continental divide in Waterton Lakes National Park, Alberta. Canadian Field-Naturalist, 105, 325-329.

Ide, R., \& Oguma, H. (2010). Use of digital cameras for phenological observations. Ecological Informatics, 5, 339-347.

Keller, M., Schimel, D. S., Hargrove, W. W., \& Hoffman, F. M. (2008). A continental strategy for the National 
Ecological Observatory Network. Frontiers in Ecology and the Environment, 6, 282-284.

McLellan, B. N., \& Hovey, F.W. (2001). Habitats selected by grizzly bears in a multiple use landscape. Journal of Wildlife Management, 65, 92-99.

Meyer, G. E., \& Neto, J. C. (2008). Verification of color vegetation indices for automated crop imaging applications. Computers and Electronics in Agriculture, 63, 282-293.

Munro, R. H. M., Nielsen, S. E., Price, M. H., Stenhouse, G. B., \& Boyce, M. S. (2006). Seasonal and diel patterns of grizzly bear diet and activity in westcentral Alberta. Journal of Mammology, 87, 11121121.

Nielsen, S. E. (2005). Habitat Ecology, Conservation, and Projected Population Viability of Grizzly Bears (Ursus arctos L.) in West-Central Alberta, Canada. Ph.D. dissertation. Edmonton, Alberta: Department of Biological Sciences, University of Alberta.

Nielsen, S. E., Boyce, M. S., Stenhouse, G. B., \& Munro, R. H. M. (2003). Development and testing of phenologically driven grizzly bear habitat models. Ecoscience, 10, 1-10.

Nielsen, S. E. , McDermid, G., Stenhouse, G. B., \& Boyce, M. S. (2010). Dynamic wildlife habitat models: Seasonal foods and mortality risk predict occupancyabundance and habitat selection in grizzly bears. Biological Conservation, 143, 1623-1634.

Persson, I. L., Wikan, S., Swenson, J. E., \& Mysterud, I. (2001). The diet of the brown bear Ursus arctos in the Pasvik Valley, northeastern Norway. Wildlife Biology, 7, 27-37.

Purcell, L. C. (2000). Soybean canopy coverage and light interception measurements using digital imagery. Crop Science, 40, 834-837.

Reed, B. C., Brown, J. F., VanderZee, D., Loveland, T. R., Merchant, J. W., \& Ohlen, D. O. (1994). Measuring phenological variability from satellite imagery. Journal of Vegetation Science, 5, 703-714.

Richardson, A. D., Jenkins, J. P., Braswell, B. H., Hollinger, D. Y., Ollinger, S. V., \& Smith, M. L. (2007). Use of digital webcam images to track spring green-up in a deciduous broadleaf forest. Oecologia, $152,323-334$.

Richardson, A. D., Braswell, B. H., Hollinger, D. Y., Jenkins, J. P., \& Ollinger, S. V. (2009). Near-surface remote sensing of spatial and temporal variation in canopy phenology. Ecological Applications, 19, 1417-1428.

Rogers, L. N. (1987). Effects of food supply and kinship on social behavior, movements, and population growth of black bears in northeastern Minnesota. Wildlife Monographs, 51, 1-72.

Schwartz, M. D., \& Reed, B. C. (1999). Surface phenology and satellite sensor-derived onset of greenness: An initial comparison. International Journal of Remote Sensing, 20, 3451-3457.

Schwartz, M. D., Reed, B. C., \& White, M. A. (2002). Assessing satellite-derived start-of-season measures in the conterminous USA. International Journal of Climatology, 22, 1793-1805.

Soudani, K., le Maire, G., Dufrêne, E., François, C., Delpierre, N., Ulrich, E., et al. (2008). Evaluation of the onset of green-up in temperate deciduous broadleaf forests derived from Moderate Resolution Imaging Spectroradiometer (MODIS) data. Remote Sensing of Environment, 112, 2643-2655.

Studer, S., Stöckli, R., Appenzeller, C., \& Vidale, P. L. (2007). A comparative study of satellite and groundbased phenology. International Journal of Biometeorology, 51, 405-414.

Waring, R. H., Coops, N. C., Fan, W., \& Nightingale, J. M. (2006). MODIS enhanced vegetation index predicts tree species richness across forested ecoregions in the contiguous U.S.A. Remote Sensing of Environment, 103, 218-226.

White, M. A., \& Nemani, R. R. (2003). Canopy duration has little influence on annual carbon storage in the deciduous broad leaf forest. Global Change Biology, 9, 967-972.

White, M. A., Running, S. W., \& Thornton, P. E. (1999). The impact of growing-season length variability on carbon assimilation and evapotranspiration over 88 years in the eastern U.S. deciduous forest. International Journal of Biometeorology, 42, 139-145.

Woebbecke, D. M., Meyer, G. E., Von Bargen, K., \& Mortensen, D. A. (1995). Color indices for weed identification under various soil, residue, and lighting conditions. Transactions of the ASAE, 38, 259-269.

Xiao, J., \& Moody, A. (2004). Photosynthetic activity of US biomes: Responses to the spatial variability and seasonality of precipitation and temperature. Global Change Biology, 10, 437-451. 